\title{
Impact of Psycho-Social Predictors on the Quality of Life of the Elderly in Pakistan
}

\author{
Naqeeb Shah ${ }^{1}$, Basharat Hussain ${ }^{2}$, Samiullah Paracha ${ }^{3}$, Muhammad Shakil Ahmad ${ }^{4}$ \\ ${ }^{1}$ Kohat University, Pakistan, naqeebhussain@kust.edu.pk \\ ${ }^{2}$ University of Peshawar,Pakistan, basharat@uop.edu.pk \\ ${ }^{3}$ Sunderland University, UK, samiullah.paracha@research.sunderland.ac.uk \\ ${ }^{4}$ Comsat University, Pakistan, onlyshakil@gmail.com
}

\begin{abstract}
This study was aimed to analyze the Quality of Life of the elderly with regard to socioeconomic conditions and psycho-social perspectives in Peshawar, Pakistan. In the present review, the focus has been made to examine the impacts of various predictors on the quality of life. A multiple indicator approach, which was based on PLS-SEM, was used to assess the impact of different psycho-socio-economic and demographic indicators on the psychological well-being of the elderly. Hypotheses were planned and evaluated for each dimension in the analysis. A self-administered questionnaire was used for data collection. Two standard inventories: Scale with Life Satisfaction and Rosenberg Self-esteem Scale were adopted and evaluated as a composite outcome measure "Quality of Life", employing Partial Least Square Structural Equation Modeling technique. The coefficient in the model showed that Social Circle, Health and General Activity have a significant contribution to the Quality of Life. The findings of the study indicated that the relationship between the explanatory variables and outcome variable was strong in the model. All constructs collectively were accounted for $68 \%$ of the amount of variance in the construct of Quality of Life. The result exhibited that the Friends and Family construct was the strongest determinant for Quality of Life and Psychological wellbeing in the retired elderly.
\end{abstract}

KEYWORDS: Quality of Life, Life Satisfaction, Self-Esteem, Leisure Activity, Social Circle, Psychological Wellbeing

\section{Introduction}

Annotations, explanations and observations regarding aging in all probability date back to the earliest times, and the documented evidence of thoughts about age can be traced back from the ancient religious literature (Roy \& Russell 2006). The depiction of aging, since the early 1970s, in literature transformed towards optimism what Constance has called "a new paradigm of hope" (Wyatt-Brown 2002). Recent times have witnessed a positive shift in life expectancy on account of modern medicine, control of epidemics, better life styles, hygiene care, and healthy nutrition (Kinsella \& Velkoff 2001; Diane, Sally Wendekos \& Feldman 2004) which have increased the life span while ameliorating the later years. Quality of life and Aging is an emerging area in the realm of social and behavioral sciences (Carstensen, 1988; Mitchell 1993; Alkema \& Alley 2006; Little et al. 2012). Efforts, across the world, are being made to acquire extended life span which is accompanied by a sustained sense of well-being, a longer period of good health, extended periods of productivity and intimate relationships.

The pace of the process of aging varies due to various factors including environment, life style and genes. The aging phenomenon is rapidly rising due to the prolonged lifespan (Blagosklonny 2010; Buchanan, Husfeldt, Berg \& Houlihan 2008). Though extended life span does not mean a quality of life or satisfaction in life but according to Rowe and Kahn (1997) "it is multidimensional, encompassing the avoidance of disease and disability, the maintenance of high physical and cognitive function, and sustained engagement in social and productive activities" the current trend of demography has altered various socio-economic parameters as Werner, Schefrin \& Bradley (2010) added that the world is encountered with a considerable accumulation of the aging population which can be referred as "the graying of the planet". This emerging issue is impacting healthcare and social policies, social security and even the socio-economic condition of a family (Sathar \& Casterline, 1998). According to a report of the United Nation, the number amplified from 8 percent in 1950 to 11 percent in 2007 and projected to touch 22 percent by 2050 . The elderly 
population is increasing at a rate of 2.6 , which is higher than the overall rate of $1.1 \%$ per year. It is projected to touch two billion by 2050 .

In Pakistani society, the increasing period of lifespan, shrinking mortality and fertility rate and rising trend of migration from rural to cities posing problems for the older people in term of overcrowded cities, substandard housing and over the burdened healthcare system. In addition, low pension, minimum social security and change in value system changing the status and role of the elderly (Sathar \& Casterline 1998). Having in view the current growing trend in population increase, it is estimated that the number of elderly people will be mounted to nearly 23.76 million by 2030 . In Pakistan, which has traditional and value-oriented culture, the elderly are treated in respected and dignified manners. They are considered as a mark of piety, esteem and wisdom. However, these values are gradually changing (Salahuddin \& Dr. Jalbani 2006), which inculcating a sense of deprivation and loneliness at societal and family level and further leading them towards dissatisfaction and uselessness. Moreover, limited pension coverage and lack of old-age benefits are pushing the elderly into poverty (Alam, Ibrar \& Khan 2016). Around 12 million older adults in Pakistan are deprived of Social Security and Universal Pension System (Index 2013). The economic self-sufficiency is availed to limited people after retirement. Regular pension is offered only to those who got retired from the government sector's jobs. The elderly are suspected to be more prone to mortality, morbidity, and disability with the aggregating numbers in coming years (Afzal, 1994; Bhamani, Karim \& Khan 2013). Such a situation of prolonged life expectancy, demographic shift, minuscule pension, lack of social safety nets, changing structure of the family system, economic dependency, migration of youth to cities, modern social trends and expulsion from job at a threshold age leading the elderly towards isolation and dejection and upsets the psycho-emotional situation and subsequently effecting their internal satisfaction and quality of life (Jalal \& Younis 2014; Topinková 2008; Jillani 2005).

Quality of life and successful aging are is a broader impression which denotes life as a whole (Bowling, 2009). These all terms are not clearly distinguished from each other rather used interchangeably (Mannel \& Dupuis 1996). Farquhar (1995) enumerated various domains for satisfied life such as close and informal interaction, family gathering, health, social activities and financial position which are more likely related while examining the quality of life. An investigation conducted by McCamish et al. (1999) added that personal and close relationships (contact with children, siblings, relatives and friends) and health (available help and subjective assessment of health) was found to be strongly significant to the satisfaction in life. Higher level of Life satisfaction, in another comparative study, was found in those living in their local communities in comparison to the elderly living in nursing homes (Gueldner et al. 2001). The five areas of functioning including economic, social, mental, ADL and physical had significant association to successful aging and life satisfaction (Krach et al. 1996). The subjective health is also fundamental domain of life quality. According to various studies, high level of life satisfaction has been found in those older people who reported excellent health (Farquhar 1995; McCamish-Svensson et al. 1999; Hilleras et al. 2001). The investigation carried out by Bondevik \& Skogstad (1996) indicated negative impact of loneliness on the elderly. Aloneness is significantly related with low quality of life (Holmen, Ericsson \& Winblad 1999). Hilleras, Herlitz, Jorm, and Winblad (2001) postulate that family and friends' interaction and support is a kind of cushion which inhibits the damaging impact on the life of the elderly. They maintained that close friendships and strong family relations tend to enhance self-esteem, strong identity and satisfaction in life. Carstensen, Gross and Fung (1997) postulated that companionship, friends and relatives in later life, keep the older people satisfied and happy.

The present work was planned in order to empirically explore the quality of life relationship with various Psycho-social variables. Aging from multiple perspectives has been studied and studying throughout the world but in Pakistan, the questioned phenomenon is a bit ignored area of research. The seriousness of the problem is not being realized and concealed under the cultural and normative cover of social system so far. But, now, public perceptions and social realities about the emerging elderly issues are changing due to urbanization, modernization, influx of information, the 
nuclearization of the family system, migration and mandatory retirement. The current study aims at enhancing the insight and assessing the quality of life of the elderly in the context of multiple psychological and social perspectives. The study also contributes to the existing knowledge by exhibiting the empirical relationship among various determinants and outcome variables.

\section{Methodology}

The current investigation was based on a descriptive study design. The sample group information was collected through the Questionnaire. The conceptual design was constituted to examine the relationship between predictors and dependent variables. In most of the previous studies the predictors of satisfaction and quality of life have been somewhat economic in nature or follow a single-criterion technique while multi-dimensional approach usually ignored. In present work, the conceptual framework was hypothesized that quality of life is a product of multiple latent constructs such as friends and family relation, social and leisure activities self-rated health, self-esteem and life satisfaction. The current study examined the association of the composite latent measure "Quality of Life" that was consisted of two standardized inventories (Satisfaction with Life Scale constituted by Diener in 1985(Diener et al. 1985) and Rosenberg Self-Esteem scale, designed by Rosenberg in 1965 (Rosenberg 1965) and four (standardized scales) latent predictors comprised of Friends \& Family Relationships, Leisure Activity, Social Activity and Self-Rated Health variables. The statistical procedure of the Case Summary and Box-Plot, according to Krzywinski \& Altman (2014) is a powerful graphing and validation tool, were used to specify and remove the outliers and missing values.

Figure 1. The Conceptual framework of the study is presented in the following model

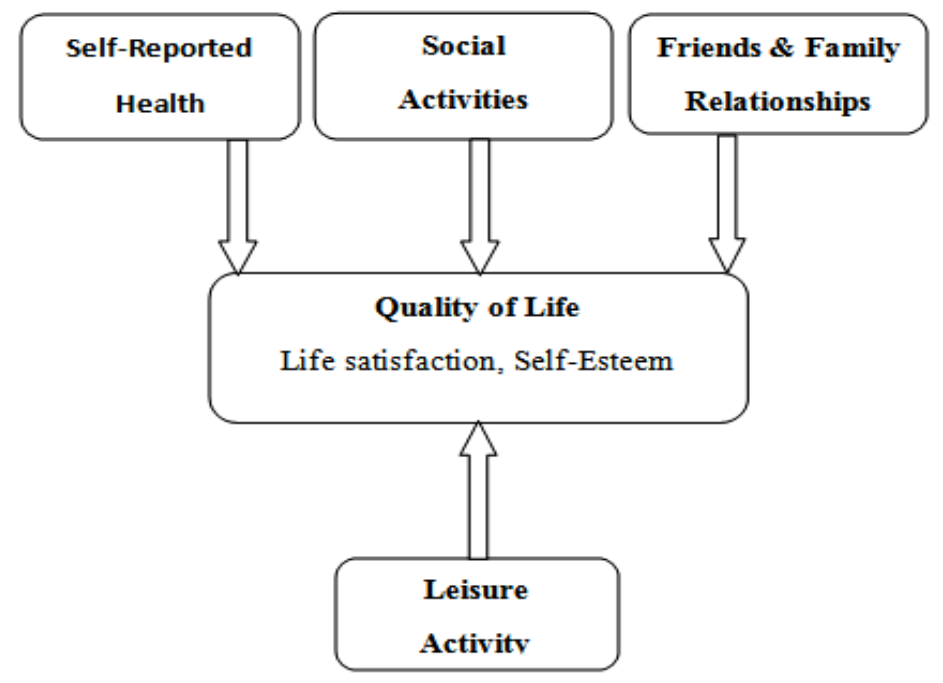

Source: Author's self-developed conceptual Model

To make sure the reliability of the survey instruments a pretest of the questionnaire was performed. The possible flaws in the questionnaire were incorporated. The validity was made sure by adopting standardized measures for collecting accurate and appropriate information of the respondents. The content validity was ensured by the consistency of the responses in pretesting. The survey instruments were constructed in both Urdu and English languages to make it more comprehensible to the elderly.

\section{Sample and Data collection}

For the collection of data, the sample population was taken from Peshawar. The data of 312 older people as a sample group were collected through convenience sampling technique. Only those respondents were selected for the study who were at the age of 60 years or above. The sample group 
was consisted of male-only respondents due to a number of constraints such as gender segregation, socio-economic disparities, and difficulties in retention and recruitment of elderly women in Pakhtun society. Only those respondents were included that were willing to partake and had no observable mental and physical disability.

\section{Analysis and Result}

All the measurement constructs were adopted from validated scales. The model contains four exogenous latent constructs with reflective measurement model and an endogenous higher order construct. higher-order construct is directly measured by indicators of all its underlying lower-order constructs (Becker, Wetzels \& Klein 2012; Wetzels, Odekerken-Schröder \& Van 2009). In this work, Quality of Life is conducted as second order construct operationalised as reflectively by two first order reflective construct i.e. $\mathrm{L}_{-} \mathrm{S}$ and $\mathrm{S}_{-}$E. the repeated indicator approach is used by assigning all the indicators of low order construct to higher order construct. The independent variables are reflectively measured by its relative indicators as first order constructs (S_A, L_A, F\&F, S_R_H). The present Model in the research is analyzed by PLS-SEM. A significant relationship was found between latent variable and their respective items in Measurement model. To evaluate the Measurement model indicator reliability, convergent validity and discriminant validity was tested. In order to achieve unidimensionality of a construct, factor loadings of all the items must be greater than 0.5 (Hair et al., 2014). Construct reliability was assessed by the value of C.R and Cronbach alpha ranging from 0.7 to 0.9. AVE was calculated to test convergent validity, threshold value of $\mathrm{AVE}>0.5$. (Hair et al, 2017; Bagozzi and Yi (1988). To examine the discriminant validity, Fornell and Lecker scale was utilized (Fornell \& Lecker 1981). Structure model is assessed by evaluating significant path coefficient and coefficient of determination which shows the relationship between construct and quality of life model (Hair et al. 2014).

In Reflective Measurement Model, convergent validity, Cronbach alpha and factor loading was assessed. All the latent variables met the required criteria. Table 1 shows that C.R and AVE values of construct exceed the threshold criterion value "0.7 and 0.5" (Bagozzi and Yi, 1988). Item loading of all the constructs were higher than 0.5 whereas items with small factor loading and nonsignificant were deleted to maintain the indicator reliability. Thus our model depicts strong and reliable convergent validity. The values of Cronbach alpha in table 1 are above the threshold value i.e. $>0.7$ concluded the good item reliability. To assess the second order construct with repeated indicator approach, first order construct was used as indicator. In Table_1 Life Satisfaction "L_S" (0.934) and Self-Esteem "S_E" (0.955) have strong and significant path coefficient to second order construct Quality of Life "QoL" explains more than 50\% variance in Life satisfaction and Self-Esteem, values of AVE $=0.542$ and $\mathrm{CR}=0.938$ are above the recommended value which indicate the validity of construct.

Table 1. Indicator Reliability of the constructs

\begin{tabular}{lcccc}
\hline Construct \& items & $\begin{array}{c}\text { Item } \\
\text { Loadin }\end{array}$ & $\begin{array}{c}\text { Cronbach's } \\
\text { Alpha }\end{array}$ & CR & AVE \\
\hline Leisure Activity & & $\mathbf{0 . 8 5 3}$ & $\mathbf{0 . 8 9 2}$ & $\mathbf{0 . 5 8 4}$ \\
L_A.10 & 0.851 & & & \\
L_A.11 & 0.837 & & & \\
L_A.12 & 0.807 & & & \\
L_A.13 & 0.592 & & & \\
L_A.8 & 0.625 & & & \\
L_A.9 & 0.827 & & & \\
Life Satisfaction & & $\mathbf{0 . 9 0 3}$ & $\mathbf{0 . 9 2 9}$ & $\mathbf{0 . 7 2 5}$
\end{tabular}



L_S1
0.903
L_S.2
0.903
L_S.3
0.875
L_S.4
0.841
L_S.5
0.721

Social Activity

S_A.1

0.808

S_A.2

0.718

S_A.3

0.618

S A.4

0.737

Self-Esteem

S E.1

0.760

S_E.10

0.802

S_E.2

0.622

S_E. 3

0.748

S_E.4

0.715

S_E.6

0.694

S_E.7

0.820

S E.9

0.661

Self Rated Health

S_R_H.1

0.831

S_R_H.2

0.646

S_R_H.3

0.764

S_R_H.4

0.844

Friend \& Family

S_R.2

0.778

S_R.4

0.673

S_R.5

0.696

S_R.6

0.817

S R.7

0.671

Quality of Life

"QoL"

Self-Esteem "S_E" 0.955

Life Satisfaction

"L S S"

0.934 $\begin{array}{lll}0.694 & 0.813 & 0.524\end{array}$

$\begin{array}{lll}0.874 & 0.901 & 0.534\end{array}$

$\begin{array}{lll}0.780 & 0.856 & 0.601\end{array}$

$\begin{array}{lll}0.780 & 0.849 & 0.532\end{array}$

$\begin{array}{lll}0.928 & 0.938 & 0.542\end{array}$

Source: Author's self-designed

Hence the convergent validity and reliability of Reflective Measurement Model is achieved. Fornell and Larcker Criterion method was used to assess the discriminant validity. In Table 2, diagonal values are AVE's square root which is greater of its corresponding correlation values. 
Table 2. Discriminant validity of Constructs

\begin{tabular}{c|cccccc}
\hline Constructs & $\begin{array}{c}\text { Friends } \\
\text { \& } \\
\text { Family }\end{array}$ & $\begin{array}{c}\text { Leisure } \\
\text { Activity }\end{array}$ & QoL & $\begin{array}{c}\text { Self-Rated } \\
\text { Health }\end{array}$ & $\begin{array}{c}\text { Social } \\
\text { Activity }\end{array}$ & $\mathbf{R}^{2}$ \\
\hline Friends \& Family & 0.729 & & & & & \\
Leisure Activity & 0.609 & 0.764 & & & & $\mathbf{0 . 6 8}$ \\
Quality of Life & 0.762 & 0.528 & 0.736 & & & \\
Self-Rated Health & 0.459 & 0.298 & 0.604 & 0.775 & & \\
Social Activity & 0.595 & 0.487 & 0.599 & 0.437 & 0.724 &
\end{tabular}

Source: Author's self-designed

\section{Structural model}

In order to assess the Structural model, collinearity issue has to be examined first. (Hair et al, 2014). Inner VIF values of all predictors construct are less than 5, suggesting that there is no collinearity among the variables. Secondly, coefficient of determination $\mathrm{R}^{2}$ has to be assessed. In our model $68 \%$ of variance in Quality of Life as shown in figure 2 can be explained by its four predictor variables i.e. Friend \& Family, Leisure Activity, Social Activity and Self-Rated Health. Thus $\mathbf{R}^{2}$ value i.e. $\mathbf{0 . 6 8}$ (Figure 2) shows that our Model has good predictive power.

Figure 2. Model of the Quality of Life

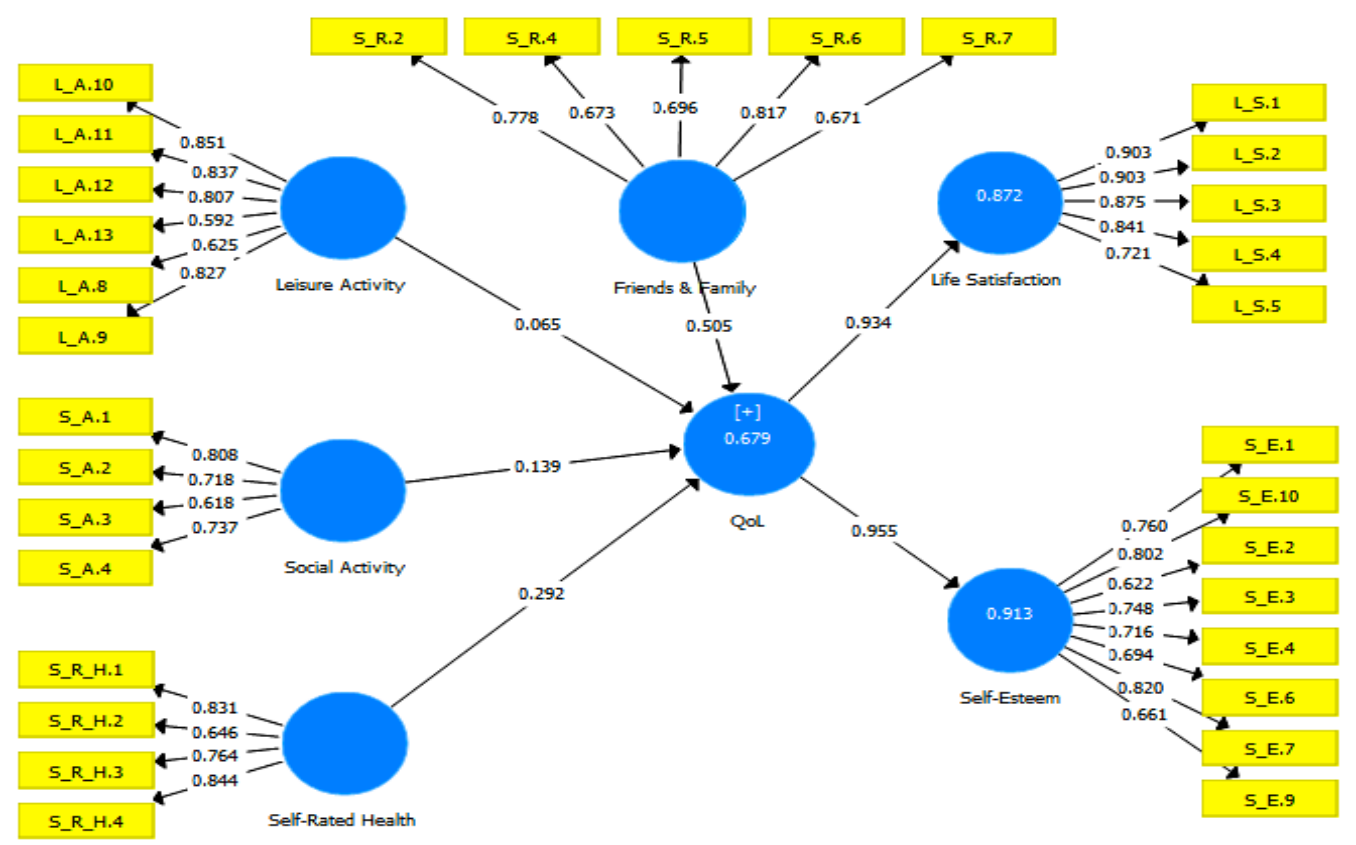

Source: Author's self-designed

The bootstrapping technique using 2000 samples was conducted for significance of path coefficient. (Ramayah et al., 2014; Chin, 2010). Table 3 shows that three out of four structural paths are significant. Friend \& Family has positive strong effect on QoL $(\beta=0.505, \mathrm{t}=10.93)$. Social Activity $(\beta=0.139$, $\mathrm{t}=2.98)$ and Self Rated Health $(\beta=0.29, \mathrm{t}=8.259)$ are positively associated with QoL. Leisure Activity shows non-significant and weak effect on the $\mathrm{QoL}(\beta=0.065, \mathrm{t}=1.59)$. 
Table 3. Path coefficient, P value and Predictive Relevance

\begin{tabular}{ccccccc}
\hline Association of Constructs & $\mathbf{B}$ & Mean & STDEV & t-value & P Values & $\mathbf{Q}^{2}$ \\
\hline Friends \& Family -> QoL & 0.505 & 0.503 & 0.046 & 10.931 & 0.000 & \\
Leisure Activity -> QoL & 0.065 & 0.066 & 0.041 & 1.588 & 0.113 & $\mathbf{0 . 3 4}$ \\
Self-Rated Health -> QoL & 0.292 & 0.295 & 0.035 & 8.259 & 0.000 & \\
Social Activity -> QoL & 0.139 & 0.139 & 0.047 & 2.980 & 0.003 & \\
\hline
\end{tabular}

Source: Author's self-designed

In PLS-SEM, predictive relevance can be calculated through blindfolding test. Chin (1998) suggests that $\mathrm{Q}^{2}$ value of greater than zero indicates good model predictive. In this study $\mathbf{Q}^{\mathbf{2}}=\mathbf{0 . 3 4}$ indicating the endogenous variable Quality of Life "QoL” was well explained by its predictors variables.

\section{Discussion}

The depth and breadth of the quality of life construct was evaluated by examining the relationships of various determinants and measures through PLS-SEM (Partial Least Square-Structural Equation Modeling). The composite perceptive measure "Quality of Life" was examined in this study to explore the influence of different Psycho-social predictors (e.g., Friends \& Family, Social Activity, Leisure Activity and Self-rated Health). According to Krach, DeVaney, DeTurk, \& Zink (1996) these domains have significant association with mental well-being. In present study, it was hypothesized that the Quality of Life is a broader, heterogeneous and multi-perspective domain of subjective measures (consisted of disposition or personality factors such as self-esteem and self-worth, pessimism and optimism and neuroticism) and objective measure (comprised of situational or environmental determinants such as friends, family, activities, leisure, health). Leung and Lee (2005) opines that Quality of Life is the product of individuals' evaluation of vital aspect of life (e.g., Social circle, social support, leisure and social activities and available resources).

The finding and the structural model of current investigation not only supported the previous work carried out in context of aging and satisfaction but also affirms the importance of relationship with friends and relatives. The findings of Diener and Diener (2002) confirms the result of this study revealing that when biological needs are fulfilled, strong social ties are enough for quality of life and satisfaction. The prior work indicates the association of health with the social integration in term of fast curing from illness, early discharge from hospitals and increased conformity with the course of therapy (DiMatteo 2004). Hilleras et al. (2001) founds that social integration and social relations are more likely to protect from harmful and distressing effect emerges over a period in one's life. It is also revealing that the people who have good friend and family relations, purposeful and healthy involvements, positive outlooks and high self-esteem are relatively live more contended and satisfied life. Carstensen et al. (1997) maintains that having close friends and companions in aging increase happiness and satisfaction in life.

The findings of the study also support the investigation of the study of Borg, Hallberg and Blomqvist (2006) who found that support by friend and family members strongly related with the satisfaction in life. Social interaction with children, siblings and friends significantly associated with quality of life and mental health (McCamish-Svensson et al. 1999). The older people who have poor social interaction and support most probably have weak self worth and dignity, lose their independentness and feel themselves as a burden. A study conducted by Taqui et al. (2007) in Pakistan revealed that ratio of depression was high in those elderly who were unmarried, separated and widowed, while Diane et al (2004) added that good ties with family and friends found to be a buffer for psychological disorder in most of the people. Osborne (2012) found that friendships, community participation and social interaction are those strong indicators which pacify and sooth the older people in difficult times. The findings of the current study indicate that the elderly who had strong relationship with friend and family were found to be more satisfied and happy. The current work shows strong relations between social integration and quality of life. 
The outcomes of the investigation, on one hand, call for social planners and policy makers to formulate workable policy proposal on the older adults' social integration and inclusion into the family and society and on the other hand, the elderly are recommended to keep intact with friends, maintain good family relationships, involve themselves into healthy and purposeful engagements and have positive and optimistic outlook for leading a satisfied, dignified and well-adjusted life.

The results of the present study, in context of limitation, are not generalizable altogether since all the respondents were selected from only one metropolitan city i.e. Peshawar. This makes result less generalizable to all the elderly who belong to the other cities of the country. Future studies may yield more encompassing and accurate results across the population.

\section{Conclusion}

Extended life span along with a sustained sense of well-being, a longer period of good health, a strong sense of productivity and close and intimate relationships pave ways for a better quality of life and successful aging. This study was planned to investigate multi-dimensional predictors in term of their influence on subjective measures of the quality of life and mental well-being of the elderly. This work found out that satisfaction and well-being is not solely the outcome of the available material resources and leisure activities but warm and close relationships with friends and relatives are also have crucial importance in the elderly life. Social network and friendly ties with closed members lead towards a respectable status and role which subsequently enhance the satisfaction level and self-worth of the older member.

\section{References}

Afzal, M. 1994. Population Ageing in Pakistan and its Implications. UN: Department for Economic and Social information and Policy Analysis.126-132.

Alam, A., Ibrar, M., \& Khan, P. 2016. "Socio-Economic and Psychological Problems of the Senior Citizens of Pakistan." Peshawar Journal of Psychology and Behavioral Sciences 2(2): 249-262.

Alkema, G. E., \& Alley, D. E. 2006. "Gerontology's future: An integrative model for disciplinary advancement." The Gerontologist, 46(5): 574-582.

Bagozzi, R. \& Yi, Y. 1988. "On the evaluation of structural equation models." Journal of the Academy of Marketing Science 16(1): 74-94.

Becker, J. M., Klein, K., \& Wetzels, M. 2012. "Hierarchical latent variable models in PLS-SEM: guidelines for using reflective-formative type models." Long Range Planning 45(5): 359-394.

Bhamani, M. A., Karim, M. S., \& Khan, M. M. 2013. "Depression in the elderly in Karachi, Pakistan: a cross sectional study." BMC Psychiatry 13(1): 181.

Blagosklonny, M. V. 2010. "Why human lifespan is rapidly increasing: solving longevity riddle" with" revealed-slow-aging" hypothesis." Aging (Albany NY) 2(4): 177.

Bondevik, M., \& Skogstad, A. 1996. "Loneliness among the oldest old, a comparison between residents living in nursing homes and residents living in the community." The International Journal of Aging and Human Development 43(3): 181-197.

Borg, C., Hallberg, I. R., \& Blomqvist, K. 2006. "Life satisfaction among older people (65+) with reduced self-care capacity: the relationship to social, health and financial aspects." Journal of Clinical Nursing 15(5): 607-618.

Bowling, A. 2009. "The psychometric properties of the older people's quality of life questionnaire, compared with the CASP-19 and the WHOQOL-OLD." Current Gerontology and Geriatrics Research 2009.

Buchanan, J., Husfeldt, J., Berg, T., \& Houlihan, D. 2008. "Publication trends in behavioral gerontology in the past 25 years: are the elderly still an understudied population in behavioral research?" Behavioral Interventions 23(1): 65-74.

Carstensen, L. L. 1988. "The emerging field of behavioral gerontology.” Behavior Therapy, 19(3): 259-281.

Carstensen, L. L., Gross, J. J., \& Fung, H. H. 1997. "The social context of Emotional Experience.” Annual Review of Gerontology and Geriatrics, Volume 17, 1997: Focus on Emotion and Adult Development, 325-352.

Chin, W.W. 1998. "Issues and opinion on structural equation modeling." MIS Quarterly 22 (1): vii-xvi. 
Chin, W.W. 2010. "How to write up and report PLS analyses." In: Vinzi, V.E., Chin, W.W., Henseler, J., Wang, H. (Eds.), Handbook of Partial Least Squares: Concepts, Methods and Applications in Marketing and Related Fields. Springer, Berlin, 655-690.

Diane, E. P., Sally Wendekos,S., \& Feldman, R. D. 2004. Human Development ( $9^{\text {th }}$ ed). New Delhi: Tata McGraw-Hill Publishing Company Limited.

Diener, E. D., Emmons, R. A., Larsen, R. J., \& Griffin, S. 1985. “The satisfaction with life scale.” Journal of Personality Assessment 49(1): 71-75.

Diener, E., \& Biswas-Diener, R. 2002. "Will money increase subjective well-being?" Social indicators research 57(2: 119-169.

DiMatteo MR. 2004. "Social support and patient adherence to medical treatment: a meta-analysis." Health Psychol 23(2): 207-218.

Farquhar, M. 1995. "Elderly people's definitions of quality of life." Social science \& medicine 41(10): 14391446.

Fornell C, Larcker DF. 1981. "Evaluating structural equation models with unobservable variables and measurement error." J Market Res 18(1):39-50.

Gueldner, S. H., Loeb, S., Morris, D., Penrod, J., Bramlett, M., Johnston, L., \& Schlotzhauer, P. 2001. "A comparison of life satisfaction and mood in nursing home residents and community-dwelling elders." Archives of Psychiatric Nursing 15(5): 232-240.

Hair, Jr, J. F., Hult, G. T. M., Ringle, C., \& Sarstedt, M. 2014. A primer on partial least squares structural equation modeling (PLS-SEM). Sage Publications.

Hair, Jr, J. F., Sarstedt, M., Ringle, C. M., \& Gudergan, S. P. 2017. Advanced issues in partial least squares structural equation modeling. SAGE Publications.

Hampton Roy,Charles Russell. 2006. Encyclopedia of aging: ideas about aging in literature. Retreived 10 Dec, 2018 from http://www.medrounds.org/encyclopedia-of-aging/2006/01/ideas-about-aging-inliterature.html.

Hilleras, P. K., Jorm, A. F., Herlitz, A., \& Winblad, B. 2001. "Life satisfaction among the very old: A survey on a cognitively intact sample aged 90 years or above." The International Journal of Aging and Human Development 52(1): 71-90.

Hilleras, P. K., Jorm, A. F., Herlitz, A., \& Winblad, B. 2001. "Life satisfaction among the very old: A survey on a cognitively intact sample aged 90 years or above." The International Journal of Aging and Human Development 52(1): 71-90.

Holmén, K., Ericsson, K., \& Winblad, B. 1999. "Quality of life among the elderly: State of mood and loneliness in two selected groups." Scandinavian Journal of Caring Sciences 13(2): 91-95.

Index, G. A. 2013. Insight report (2013). Help Age International.

Jalal, S., \& Younis, M. Z. 2014. “Aging and elderly in Pakistan.” Ageing International 39(1): 4-12.

Jillani M.S. 2005. Changing times for the elderly. Retreived Sep,2015 from https://msjillani.wordpress.com/2009/01/21/changing-times-for-the-elderly/.

Kinsella, K., \& Velkoff, V. U. S. 2011. Census Bureau. An Aging World: 2001. Washington, DC: US Government Printing Office, 2001. series P95/01-1.

Krach, P., DeVaney, S., DeTurk, C., \& Zink, M. H. 1996. "Functional status of the oldest - old in a home setting." Journal of Advanced Nursing 24(3): 456-464.

Krzywinski, M., \& Altman, N. 2014. Points of significance: visualizing samples with box plots. Nature Methods 11:119-120.

Leung, L., \& Lee, P. S. 2005. "Multiple determinants of life quality: The roles of Internet activities, use of new media, social support, and leisure activities." Telematics and Informatics 22(3): 161-180.

Little, W., Vyain, S., Scaramuzzo, G., Cody-Rydzewski, S., Griffiths, H., Strayer, E., \& Keirns, N. 2012. Introduction to Sociology-1 st Canadian edition. BC Open Textbook project.

Mannel, R. C., \& Dupuis, S. 1996. "Life satisfaction." In J. E. Birren, (Ed.), Encyclopedia of gerontology age, aging, and the aged (pp. 59-64). San Diego: Academic.

McCamish-Svensson, C., Samuelsson, G., Hagberg, B., Svensson, T., \& Dehlin, O. 1999. "Social relationships and health as predictors of life satisfaction in advanced old age: results from a Swedish longitudinal study." The International Journal of Aging and Human Development 48(4): 301-324.

McCamish-Svensson, C., Samuelsson, G., Hagberg, B., Svensson, T., \& Dehlin, O. 1999. "Social relationships and health as predictors of life satisfaction in advanced old age: results from a Swedish longitudinal study." The International Journal of Aging and Human Development 48(4): 301-324. 
Mitchell, O. S. 1993. Retirement Systems in Developed and Developing Countries: Institutional Features, Economic Effects, and Lessons for Economies in Transition (No. w4424). National Bureau of Economic Research.

Osborne, J. W. 2012. "Psychological Effects of the Transition to Retirement/Effets psychologiques de la transition vers la retraite." Canadian Journal of Counselling and Psychotherapy (Online) 46(1): 45.

Ramayah, T., Chiun, L. M., Rouibah, K., \& May, O. S. 2014. "Identifying priority using an importanceperformance matrix analysis (ipma): The case of internet banking in Malaysia." International Journal of E-Adoption (IJEA) 6(1): 1-15.

Rosenberg, M. 1965. Society and the adolescent self-image. Princeton, NJ: Princeton University Press.

Rowe, J. W., \& Kahn, R. L. 1997. Successful aging. The gerontologist 37(4): 433-440.

Salahuddin, K., \& Jalbani, A. A. 2006. Senior Citizens: A Case Study of Pakistan. Journal of Independent Studies and Research (JISR) 4(2): 26.

Sathar, Z. A., \& Casterline, J. B. 1998. "The onset of fertility transition in Pakistan." Population and Development Review, 773-796.

Taqui, A. M., Itrat, A., Qidwai, W., \& Qadri, Z. 2007. "Depression in the elderly: Does family system play a role? A cross-sectional study." BMC psychiatry 7(1): 57.

Topinková, E. 2008. "Aging, disability and frailty." Annals of Nutrition and Metabolism, 52 (Suppl. 1), 6-11.

Werner, J. S., Schefrin, B. E., \& Bradley, A. 2010. "Optics and vision of the aging eye." Handbook of optics, 3, 13-1.

Wetzels, M., Odekerken-Schröder, G., \& Van Oppen, C. 2009. Using PLS path modeling for assessing hierarchical construct models: Guidelines and empirical illustration, MIS quarterly 33(1): 177-195.

Wyatt-Brown. A.M. 2002. Encyclopedia of Aging: Literature and Aging. Retrieved 10, Dec, 2018 from https://www.encyclopedia.com/education/encyclopedias-almanacs-transcripts-and-maps/literatureand-aging. 